\title{
The significance of the adenosinergic system in morphine dependence
}

\author{
Malgorzata Lupina, JoAnNa Listos*
}

Department of Pharmacology and Pharmacodynamics, Medical University of Lublin, Chodźki 4a St., 20-093 Lublin, Poland

\section{ARTICLE INFO \\ Received 29 July 2015 \\ Accepted 19 August 2015}

\section{Keywords:}

adenosine,

morphine,

dependence.

\begin{abstract}
Addiction is a chronic and recurrent disease. In its pathology, neuroadaptive changes within the dopaminergic pathways inside the mesolimbic system play a predominant role. Of note, the manner in which various neurotransmitters act on their receptors, may modulate the addictive process. Adenosine, an important neuromodulator in the central nervous system, is able to modify the opioid dependence, doing so mainly by its activity on the adenosine $\mathrm{A} 1$ and $\mathrm{A} 2 \mathrm{~A}$ receptors. In the present manuscript, the actual state of knowledge on the relationships between adenosinergic receptors and opioid dependence has been described. Various literature data on the involvement of adenosine ligands, mainly in the signs of morphine withdrawal, as well as morphine-induced sensitization, were also collected. Additionally, in this paper, some important interactions between adenosine and other neurotransmitters (e.g. dopamine, glutamate) are described. It is put forward that these connections are the major mechanism of involvement of the adenosinergic system in morphine addiction. The repeatedly confirmed effectiveness of adenosine ligands in morphine dependence, as seen in various experimental protocols, suggests that adenosine ligands may be useful tools for developing new strategies for attenuating morphine dependence.
\end{abstract}

\section{ENDOGENOUS ADENOSINE AS AN IMPORTANT NEUROMODULATOR IN THE CENTRAL NERVOUS SYSTEM}

An adenosine is an endogenous purine nucleotide that consists of an adenine (purine base) and a ribose (sugar residue). This is a compound which is commonly found in the body and determines many physiological processes therein.

Adenosine is a neuromodulator in the central nervous system which acts by way of stimulating the four types of receptors, namely: A1, A2A, A2B, A3. The stimulation of the $\mathrm{A} 1$ and $\mathrm{A} 3$ receptors inhibits adenylate cyclase, while the stimulation of the adenosine $\mathrm{A} 2 \mathrm{~A}$ and $\mathrm{A} 2 \mathrm{~B}$ receptors results in the activation of that compound [58]. Of note: the activity of these receptors is associated with the secondary relay system - G-protein [31].

The largest number of the adenosine A1 receptors is in the brain, specifically in the cerebral cortex, hippocampus and cerebellum. In the striatum, they are located on the

\footnotetext{
* Corresponding author

e-mail: a.listos@umlub.pl

tel.:+48 814487250 , fax.: +48815357371
}

same neurons as the dopaminergic receptors D1 [24]. In the peripheral nervous system, A1 receptors are mainly present in the adipose tissue. They can also be found in the cells of the kidney, adrenal, the sinoatrial and atrioventricular nodes of heart, the ventral horn of the spinal cord, and the thyroid gland. A lower density of A1 adenosine receptors is also observed in the liver, pancreas, the heart chambers and the lungs [31].

A stimulation of the $\mathrm{A} 1$ adenosine receptors induces various pharmacological effects. These are largely caused by the inhibition of neurotransmitter release in the central nervous system. Among the neurotransmitters affected are the excitatory amino acids [15], dopamine [74] and noradrenaline [5]. Thus, sedation and decrease in locomotor activity is observed after treatment with the adenosine A1 agonist. Moreover, the stimulation of the A1 adenosine receptors located in the hippocampus is connected with the anticonvulsant activity of adenosine [58], and the activation of these receptors in the spinal cord reduces the transmission of presynaptic pulses to the gelatinous substance in the spinal cord, inducing analgesia [61]. 
The most important effects of the adenosine A1 agonists in the peripheral nervous system are their direct and indirect inhibitory impacts on cardiac function. This direct action includes loss of strength and frequency rate of the heart, as well as a decrease in conductivity by way of the stimulation of the A1 receptors in the sinoatrial and atrioventricular nodes of the heart [7]. The indirect action is connected with a reduction in the adenylate cyclase activity. This leads to a reduction in the activity of $\beta$-adrenergic receptors, and in the subsequent inhibition of cardiac activity [66]. In addition, the stimulation of these receptors induces a cardioprotective effect [52], and also reduces the renin release. Moreover, it decreases the glomerular filtration rate, bringing about an antidiuretic effect [72]. Furthermore, the A1 adenosine receptor agonists potentiate the activity of insulin on glucose transport [69], initiate antilipolytic activity [18] and inhibit gastric acid secretion [18].

The $\mathrm{A} 2$ adenosine receptors can be sub-classified as either the $\mathrm{A} 2 \mathrm{~A}$ and $\mathrm{A} 2 \mathrm{~B}$ receptors. Of these, the $\mathrm{A} 2 \mathrm{~A}$ receptors are significantly better recognizable. A2A receptors are mainly concentrated within the dopaminergic brain areas, such as the striatum, tuberculum factorium and the nucleus accumbens (NAc) $[33,47]$. A high density of the A2A receptors is particularly evident on the $\gamma$-aminobutyricacid (GABA) ergic neurons - both in the striatum and the globus pallidus [62]. Here, dopamine D2 receptors can also be seen [27]. The coexistence of A2A, D2 and GABAergic receptors is responsible for the close interaction between the adenosine - dopamine-GABAergic pathways in the central nervous system. For example, the stimulation of the A2A receptors induces a reduction in affinity for the dopamine D2 receptor in the striatum [25], while the application of dopamine to the striatum inhibits the release of GABA in the globus pallidus - and this effect is blocked by endogenous adenosine. Furthermore, in experimental work, the stimulation of $\mathrm{A} 2 \mathrm{~A}$ receptors has been seen to enhance GABA release from slices of the globus pallidus $[50,65]$. The relationships between A2A and D2 receptors have also been confirmed in behavioral experiments. Such work has demonstrated that both A2A agonists and D2 antagonists induce sedation and catalepsy $[26,46]$. Moreover, the blockage of adenosine A2A receptors within the striatum weakens the symptoms of Parkinson's disease, and also enhances the effect of levodopa, which is commonly used to treat this illness [71]. It is also known that $\mathrm{A} 2 \mathrm{~A}$ receptor agonists and neuroleptics are used together as antipsychotics in treating schizophrenia, due to the interaction between A2A and D2 receptors $[21,24]$.

The activation of $\mathrm{A} 2 \mathrm{~A}$ adenosine receptors also brings about certain peripheral effects, the most important of these being the normalization of blood pressure. This is effected through inducing hypotension, by bringing about the extension of the light coronary vessels, as well as the vessels in the central nervous system and the afferent renal vascular. Additionally, the A2A receptors share in the inhibition of platelet aggregation and in the conduction of pain [39].

Both, adenosine A2B and A3 receptors are poorly recognized, and their significance in various clinical problem requires further experimentation. A2B receptors are located in the human fibroblasts, the colon, caecum, gall bladder, eye, blood vessels and the lungs, while small amounts are distributed throughout the brain $[31,47]$. As literature data have suggested, the receptors within the fibroblasts may play an important role in the proliferation and differentiation of cells, and may be important for the inhibition of vascular remodeling during myocardial infarction or hypertension [22]. Moreover, the A2B receptors block the release of tumor necrosis factor (TNF- $\alpha$ ), which is produced by the monocytes [53] and which participates in the apoptosis of the vascular smooth muscle [56].

The adenosine A3 receptors [41] are found primarily in the mastocytes, while a less number are located inside the lungs, spleen, cerebellum, hippocampus and the region of the pineal gland. Moreover, a lower density of these receptors is evident in the thyroid, spleen, kidney, heart, gut, liver, adrenal gland and in many areas of the brain [31]. These receptors are active in the inflammatory processes, as they have an effect upon the inflammatory cells (the macrophages, monocytes, eosinophils and neutrophils) [30]. Additionally, A3 receptors are involved in cytoprotective activity during myocardial ischemia [37]. Furthermore, the stimulation of adenosine A3 receptors may be important in a number of neuroprotective processes within the central nervous system, as this brings about a decrease in the glutamate level inside the brain [6]. It is also known that triggering of the A3 receptors leads to the inhibition of various cell proliferation activity [29].

\section{NEUROBIOLOGY OF MORPHINE ADDICTION}

Addiction is a chronic and recurrent disease. This is induced by the interaction of a psychoactive substance and a living organism. It develops as a result of the taking of psychoactive substances, either occasionally or continuously for any purpose other than social or therapeutic [59].

Various dependent drugs bring about pleasure by stimulating dopamine release in the mesolimbic system. The mesolimbic system consists of several structures, such as the ventral tegmental area (VTA), that send projections to the NAc, amygdala, hippocampus, the ventro-anterior part of the caudatus nucleus and the prefrontal cortex $[19,45]$. Although, for many years, the VTA, NAc and hippocampus were thought to be the most important brain areas involved in the addictive process, in recent years, scientists have focused their research on the importance of the amygdala in addiction. In such work, they have demonstrated that the amygdala has a key function in the acute reinforcing actions of drugs of abuse, including the opioids [38], and is considered to be critical for the affective component of acute and chronic opiate withdrawal [34]. Indeed, recent literature data indicate that the addictive process is mainly brought about by neuro-adaptations within various neurotransmitters located within the mesolimbic system.

Morphine and other opioid acts on the opioid receptors, and induce a broad spectrum of pharmacological activity. These have both central and peripheral effects on the human body. The major action of morphine is analgesia - which is useful for clinical practices. Morphine also produces many important side effects, such as respiratory depression, sedation, as well as particular effects on pituitary hormone release or miosis. The initial dose of morphine can cause 
dysphoria, but prolonged administration of morphine and other opioids induces a strong euphoria, which leads to chronic use and dependence [68].

The effect of morphine is closely related to the stimulation of the opioid receptors. These belong to a group of metabotropic receptors that are G-protein coupled. Among the opioid receptors, there are three types: $\mu, \kappa \mathrm{i} \delta$. Pharmacological studies also point to the existence of their subtypes: $\mu_{1}, \mu_{2}, \kappa_{1} \kappa_{2}, \kappa_{3}, \delta_{1}, \delta_{2}$. Administration of therapeutic doses of opioid compounds initiates postsynaptic activation of the potassium channels, presynaptic calcium channel blockage and the reduction of adenylate cyclase activity [4].

The rewarding effect of morphine is associated with the stimulation of $\mu$ opioid receptors located on GABAergic interneurons in the VTA [67]. This stimulation of the $\mu$ opioid receptors leads to the inhibition of the GABA receptors, and, consequently, the activation of dopaminergic neurons in the NAc [20].

As studies show, the observed effects of morphine are due to the effects of its administration upon various neurotransmitter systems. For example, the NMDA receptors (which are abundant in the brain) are known to be closely associated with the process of addiction [54]. Indeed, the blockage of these receptors brings about a weakening of the development of tolerance to the analgesic effect of morphine and impairs the locomotor sensitization triggered by addictive substances in general. The close relationship between the glutamatergic system and a sensitization to opioid, cocaine and amphetamine activity was described by Vanderschuren and Kalivas (2000) [70]. The serotoninergic system also has some significance in addiction. Namely, the weakening of the serotoninergic system is associated with increased incentives to take addictive drugs, so there is then an increased risk of developing addiction. For example, it was experimentally confirmed in animals that morphine withdrawal signs were attenuated by the 5-HT7 receptor agonist [64]. Moreover, older experiments have demonstrated that the stimulation of serotonin transmission in either the VTA or NAc promotes accumbal dopamine release [12]. Apart from the glutamate or serotonin, some neuromodulators, such as adenosine, may also be involved in morphine addiction.

\section{THE SIGNIFICANCE OF ADENOSINERGIC SYSTEM IN THE ADDICTIVE EFFECTS OF MORPHINE}

As literature data reveal, adenosine, being the most important inhibitory neuromodulator in the central nervous system, is highly involved in the effect of morphine. This was repeatedly confirmed both in behavioral and molecular experiments. Moreover, many such experiments have demonstrated the influence of the agonists and antagonists of the adenosine receptors on the withdrawal symptoms in rats addicted to morphine. In such work, the characteristic features for morphine withdrawal syndrome in rats, i.e. body shakes and attempted escape, were frequently observed. In general, these studies reveal that adenosine receptor agonists attenuate withdrawal symptoms, while antagonists of the adenosine system intensify them. Of significance, N6(R-phenylisopropyl) -adenosine (R-PIA) reduces the number of jumps, while the body shakes are minimized only at the highest dose [51]. In addition, 2-chloroadenosine (2-CADO) [51] and dipirydamole [51] do not affect the escape attempts, and only some doses of such bring about a reduction in the number of body shakes. However, N6-cyclohexyladenosine (CHA) inhibits the body shakes, but does not affect attempts to escape [51]. Furthermore, A 5 '- (- N-ethyl) -carboxamido-adenosine (NECA) limits both behaviors [51]. What is more, the non-selective adenosine receptor antagonists - caffeine [51] and theophylline [51] - intensifies escape attempts and does not affect the number of body shakes, except for the highest dose of theophylline, which turns out to diminish it [51]. Such studies were also performed on mice. Namely, to ascertain R-PIA potentiated morphine dependence, and in such work, higher doses reduce the number of jumps [2]. Studies carried out in mice concerning the impact of theophylline on morphine dependence are, however, diversified in their results. Collier and Francis (1975) [14] and Ho et al., (1975) [32] claim that theophylline enhances the development of morphine dependence in mice, yet Brailowsky et al., (1981) demonstrate that theophylline inhibits it [8]. Ahlijanian and Takemori (1986), in their general studies in mice, also gained conflicting results: in some, caffeine reduced the dependence of morphine [3], and in others, it increased it [2]. All these results suggest that an important relationship exists between opioid receptors and the adenosinergic system.

In order to investigate the impact of the agonists and antagonists of the adenosine receptors on the rewarding properties of addictive substances, the conditioned place preference test (CPP) was utilized in certain experiments. This is one of the more frequently used models employed in assessing the performance of reward action [11]. These studies have shown that adenosine receptor agonists have significant effect on addiction. In such work, it was revealed that the selective A1 receptor agonist, N6-cyclopentyladenosine (CPA), and the non-selective $\mathrm{A} 1$ and $\mathrm{A} 2$ receptor agonist, NECA, weaken the acquisition of the morphine CPP, even if lower doses are administered, but the selective A2 agonist, 3-[4-[2-[ [6-amino-9-[(2R,3R,4S,5S)5-(ethylcarbamoyl)-3,4-dihydroxy-oxolan-2-yl]purin-2-yl] amino]ethyl]phenyl]propanoic acid (CGS 21680), does not produce any effect [42]. Interestingly, the selective A1 cyclopentyltheophylline (CPT) and A2A - 3,7-dimethyl1-propargylxanthine (DMPX) adenosine antagonists and the non-selective ligand, caffeine, were also seen to inhibit the acquisition of the morphine place preference [42]. Another pattern demonstrating the pharmacological activity of adenosine ligands was observed in the expression of morphine place preference. Herein, particular selective and non-selective agonists (CPA, CGS 21680 and NECA) were found to block the expression of morphine place preference, while certain selective and non-selective adenosine antagonists (CPT, DMPX and caffeine) were noted as intensifying the expression of morphine place preference [42].

In another experimental protocol, CGS 21680 and NECA were demonstrated as attenuating the development of hypersensitivity to acute doses of morphine [43]. This result supports the role of A2A receptors in such a hypersensitivity.

Less recent findings were controversial in their reported effect of the adenosine system in addiction. Namely, 
Matsuda (1970) [49] showed that the combined administration of caffeine and morphine blocks the development of opioid tolerance to opioids. Moreover, Brailowsky et al. (1981) [8] revealed that theophylline, the non-selective adenosine receptor antagonist, blocks the development of morphine addiction in mice. However, Capasso (2000) demonstrated that the $\mathrm{A} 2 \mathrm{~A}$ antagonist reduces the morphine withdrawal syndrome, while caffeine enhances it [10].

The involvement of the adenosinergic system in the activity of morphine was also confirmed by way of molecular experiments. Herein, a significant increase in the number of A1 receptors [35], in the amount of adenosine transporters [36] and in adenosine sensitivity in NAc [9] was observed after chronic morphine treatment. What is more, chronic opioid exposure was shown to bring about an increase in the number of A1 receptors in the homogenates of the entire brain [1], and, in particular, the cortex [24]. However, there are opposing results regarding the number of A2A receptors. According to De Montis (1992), chronic opioid administration induces a decrease in the number and function of the striatum A2A receptors [17], yet, Kaplan (1994) puts forward that, in mice, the number of $\mathrm{A} 2 \mathrm{~A}$ receptors in the striatum is unaltered after chronic morphine treatment [35].

Taken all these results together, it may be concluded that chronic morphine exposure is closely associated with induced changes in the adenosinergic system, and that this system is strongly involved in the activity of morphine. Considering the potential mechanisms which may underlie this relationship, several notions should be take into account.

First, we must consider the distribution of adenosine A1 and $\mathrm{A} 2 \mathrm{~A}$ receptors in the central nervous system and their adaptive changes after chronic opioid treatment. Physiologically, A1 receptors are abundant within the entire brain. However, after morphine exposure, some adaptive changes may develop, mainly in the adenosine A1 receptors. The activity of $\mathrm{A} 1$ receptors is associated with reducing the release of different neurotransmitters inside the central nervous system, and, in this way, with reducing neuronal activity inside the brain [63]. However, the co-localisation of adenosine A2A and dopamine D2 in the GABAergic neurons located within the striatum and the globus pallidus may be responsible for the close interaction between the adenosine - dopamine - GABAergic pathways in the central nervous system. These interactions also seem to be implicated in the connection between adenosinergic system activity and morphine addiction, the more that the existence of the interactions between A2A and glutamatergic, dopamine D2 or cannabinoid $\mathrm{CB} 1$ receptors are well described [for ref., see 63].

Second, apart from the observed neuroadaptive changes in the adenosinergic system, other mechanisms seem to be engaged in the activity of adenosine in morphine addiction. Several findings demonstrate that during morphine-induced sensitization, alterations in the dopaminergic and glutamatergic receptors come about within some brain areas (in the VTA, NAc, prefrontal cortex, amygdala and hippocampus) $[70,73]$. It is, moreover, likely that the neuro-adaptive changes in dopamine receptors, as well as in the glutamate receptors, may play an important role in the effect of adenosine ligands in morphine dependence. This is especially so in that both the dopamine and glutamate receptors are closely linked to the adenosine receptors, and in that the interaction between dopamine-adenosine receptors and glutamateadenosine receptors [for ref. see 63] are well described.

With respect to adenosine receptor interactions, the most recognized is that of the interaction between the A2A and D2 receptors, described by Ferré et al., in 1999 [25]. Accordingly, as seen in rat striatal membranes, the activation of A2A receptors decreases the affinity of dopamine D2 receptors. Follow-on studies undertaken five years later by Ferré et al., (1996) [23] described the interaction between A1 and D1 receptors in the basal ganglia, and showed that in different areas of the brain, this was important for GABA release control [55]. In addition, interactions between adenosine and glutamate receptors have also been demonstrated. In such work, low adenosine concentrations were shown to stimulate A1 receptors and, then, to inhibit glutamate release from the glutamatergic nerve terminals. What is more, low adenosine concentrations evidently inhibit NMDA receptors in the hippocampal pyramidal neurons [16], and restrict voltage- and NMDA receptor-sensitive dendritic spikes in the CA1 area of the hippocampus [40]. Furthermore, A2A receptors, located in glutamatergic synapses, control the release of glutamate in the striatum, the cerebral cortex and the hippocampus $[13,44,48]$, as well as NMDA receptor activity in the striatum [57].

To conclude, the presented results of major studies demonstrate the involvement of the adenosinergic system in morphine addiction. Furthermore, the work of many authors show that adenosine, acting on adenosine receptors, is able to induce a broad spectrum of pharmacological activity which may be helpful in the therapy of various clinical pathologies, including morphine addiction. In view of the above findings, it can be suggested that adenosine ligands may be useful tools in attenuating morphine dependence.

\section{REFERENCES}

1. Ahlijanian M.K., Takemori A.E.: Changes in adenosine receptor sensitivity in morphine-tolerant and - dependent mice. J. Pharmacol. Exp. Ther., 236, 615-620, 1986.

2. Ahlijanian M.K., Takemori A.E.: Effects of /-/-N ${ }^{6}-(\mathrm{R}-$ phenylisopropyl)-adenosine (R-PIA) and caffeine on nociception and morphine-induced analgesia, tolerance and dependence in mice. Eur. J. Pharmacol., 112, 171-179, 1985.

3. Ahlijanian M.K., Takemori A.E.: The effect of chronic administration of caffeine on morphine-induced analgesia, tolerance and dependence in mice. Eur. J. Pharmacol., 120, 25-32, 1986.

4. Al-Hasani R., Bruchas M.R.: Molecular Mechanisms of Opioid Receptor-Dependent Signaling and Behavior. Anesthesiology, 115(6), 1363-1381, 2011.

5. Allgaier C., Hertting G., Kügelgen O.V.: The adenosine receptormediated inhibition of noradrenaline release possibly involves an $\mathrm{N}$-protein and is increased by alpha 2-autoreceptor blockade. $\mathrm{Br}$. J. Pharmacol., 90(2), 403-412, 1987.

6. Barth A. et al.: Neurotoxicity in organotypic hippocampal slices mediated by adenosine analogues and nitric oxide. Brain Res., 762, 79-88, 1997.

7. Belardinelli L., Linden J., Berne R.M.: The cardiac effects of adenosine. Prog. Cardiovasc. Dis., 32, 73-97, 1989.

8. Brailowsky S. et al.: Morphine-theophylline interaction: antagonism or facilitation? Br. J. Pharmacol., 73, 887-92, 1981.

9. Brundege J.M., Williams J.T.: Increase in adenosine sensitivity in the nucleus accumbens following chronic morphine treatment. J. Neurophysiol., 87, 1369-1375, 2002. 
10. Capasso A.: Adenosine receptors are involved in the control of acute naloxone-precipitated withdrawal: in vitro evidence. Life Sci., 66, 873-883, 2000.

11. Carr G.D., Fibiger H.C., Phillips A.G. (1989). Conditioned place preference as a measure of drug reward. In: The neuropharmacological basis of reward. Lieberman J.M., Cooper S.J.(editors). Oxford: Oxford University Press; p. 264-319.

12. Chen J., Van Praag H.M., Gardner E.L.: Activation of 5-HT, receptor by 1-phenylbiguanide increases dopamine release in the rat nucleus accumbens. Brain Res., 543, 354-357, 1991.

13. Ciruela F. et al.: Presynaptic control of striatal glutamatergic neurotransmission by adenosine A1-A2A receptor heteromers. $J$. Neurosci., 26, 2080-2087, 2006.

14. Collier H.O.J., Francis D.L.: Morphine abstinence is associated with increased brain cyclic AMP. Nature, 255, 159-162, 1975.

15. Coradetti R. et al.: Adenosine decreases aspartate and glutamate release from rat hippocampal slices. Eur. J. Pharmacol., 104, 19-26, 1984.

16. de Mendonça A., Sebastião A.M., Ribeiro J.A.: Inhibition of NMDA receptor-mediated currents in isolated rat hippocampal neurones by adenosine A1 receptor activation. Neuroreport, 6, 1097-1100, 1995.

17. De Montis M.G. et al.: Decreased adenosine $A_{2}$ receptor function in morphine dependent rats. Pharmacol. Res., 25, 232-233, 1992.

18. Dhalla A.K. et al.: Pharmacology and therapeutic applications of A adenosine receptor ligands. Curr. Top. Med. Chem., 3, 369-385, 2003.

19. DiChiara G., Imperato A.: Drugs abused by humans preferentially increase synaptic dopamine concentrations in the mesolimbic system of freely moving rats. Proc. Natl. Acad. Sci. USA., 85, 5274-5278, 1988.

20. DiChiara G., Imperato A.: Opposite effects of mu and kappa opiate agonist on dopamine release in the nucleus accumbens and in the dorsal caudate of freely moving rats. J. Pharm. Exp. Ther., 244, 10671080, 1988.

21. Dixon D.A. et al.: Indirect modulation of dopamine $\mathrm{D}_{2}$ receptors as potential pharmacotherapy for schizophrenia: I. Adenosine agonists. Ann. Pharmacother., 33(4), 480-488, 1999.

22. Dubey R.K. et al.: Exogenous and endogenous adenosine inhibits fetal calf serum-induced growth of rat cardiac fibroblasts: Role of A2B receptors. Circulation, 96, 2656-2666, 1997.

23. Ferré S. et al.: Adenosine A1 receptor-dopamine D1 receptor interaction in the rat limbic system: modulation of dopamine D1 receptor antagonists binding sites. Neurosci. Lett., 208, 109-112, 1996.

24. Ferré S.: Adenosine - dopamine interactions in the ventral striatum. Implications for the treatment of schizophrenia. Psychopharmacology, 133, 107-120, 1997.

25. Ferré S. et al.: Stimulation of high-affinity adenosine $A_{2}$ receptors decreases the affinity of dopamine D2 receptors in rat striatal membranes. Proc. Natl. Acad. Sci. USA., 88, 7238-7241, 1991.

26. Ferré S., Rubio A., Fuxe K.: Stimulation of adenosine A2 receptors induces catalepsy. Neurosci. Lett., 130, 162-164, 1991.

27. Fink J.S. et al.: Molecular cloning of the rat A2 adenosine receptor: selective co-expression with D2 dopamine receptors in rat striatum. Brain. Res. Mol. Brain Res., 14, 186-195, 1992.

28. Fishman P. et al.: Adenosine acts as a chemoprotective agent by stimulating G-CSF production: a role for A1 and A3 adenosine receptors. J. Cell Physiol., 183, 393-398, 2000.

29. Fishman P. et al.: The A3 adenosine receptor as a new target for cancer therapy and chemoprotection. Exp. Cell Res., 269, 230-236, 2001.

30. Fishman P., Bar-Yehuda S.: Pharmacology and therapeutic applications of A3 receptor subtype. Curr. Top. Med. Chem., 3, 463-469, 2003

31. Fredholm B.B. et al.: International Union of Pharmacology. XXV. Nomenclature and classification of adenosine receptors. Pharmacol. Rev., 53, 527-552, 2001.

32. Ho E.L. et al.: Effect of cyclic nucleotides and phosphodiesterase inhibition on morphine tolerance and physical dependence. Life Sci., 16, 1895-1900, 1975.

33. Jarvis M.F., Williams M.: Direct autoradiographic localization of adenosine A2 receptors in the rat brain using the A2 selective agonists, [ $\left.{ }^{3} \mathrm{H}\right]$-CGS 21680. Eur. J. Pharmacol., 168, 243-246, 1989.
34. Jin C. et al.: Withdrawal-induced c-Fos expression in the rat centromedial amygdala $24 \mathrm{~h}$ following a single morphine exposure. Psychopharmacology, 175, 428-435, 2004.

35. Kaplan G.B., Leite-Morris K.A., Sears M.T.: Alterations in adenosine A1 receptors in morphine dependence. Brain Res., 657, 347-350, 1994.

36. Kaplan G.B., Leite-Morris K.A.: Up-regulation of adenosine transporter-binding sites in striatum and hypothalamus of opiate tolerant mice. Brain Res., 763, 215-220, 1997.

37. Kitakaze M., Hori M.: Adenosine therapy: a new approach to chronic heart failure. Expert Opin. Investig. Drugs., 9, 2519-2535, 2000.

38. Koob G.F., Volkow N.D.: Neurocircuitry of addiction. Neuropsychopharmacology, 35, 217-238, 2010.

39. Ledent C. et al.: Aggressiveness, hypoalgesia and high blood pressure in mice lacking the adenosine A2A receptor. Nature, 388, 674-678, 1997.

40. Li H., Henry J.L.: Adenosine receptor blockade reveals N-methyl$\mathrm{D}$-aspartate receptor- and voltage-sensitive dendritic spikes in rat hippocampal CA1 pyramidal cells in vitro. Neuroscience, 100, 21-31, 2000.

41. Linden J.: Molecular approach to adenosine receptors: receptormediated mechanisms of tissue protection. Annu. Rev. Pharmacol. Toxicol., 41, 775-787, 2001.

42. Listos J., Poleszak E., Malec D.: The influence of adenosine receptor agonists and antagonists on morphine place preference in rats. Annales UMCS, Pharmacia, sectio DDD, 15(1), 185-200, 2002.

43. Listos J., Talarek S., Fidecka S.: Involvement of adenosine receptor agonists on the development of hypersensitivity to acute dose of morphine during morphine withdrawal period. Pharmacol Rep. 60(5), 679-685, 2008.

44. Lopes L.V. et al.: Adenosine $\mathrm{A}(2 \mathrm{~A})$ receptor facilitation of hippocampal synaptic transmission is dependent on tonic $\mathrm{A}(1)$ receptor inhibition. Neuroscience, 112, 319-329, 2002.

45. Maldonado R.: The neurobiology of addiction. J. Neural. Transm., 66, 1-14, 2003.

46. Malec D., Poleszak E.: Cataleptogenic activity of adenosine analogues in rats. Annales UMCS section DDD, 11, 51-63, 1998.

47. Malec D.: Purinergic receptors. Pol. J. Pharmacol., 48, 457-465, 1996.

48. Marchi M. et al.: Effects of adenosine A1 and A2A receptor activation on the evoked release of glutamate from rat cerebrocortical synaptosomes. Br. J. Pharmacol., 136, 434-440, 2002.

49. Matsuda K.: Experimental studies on the effective procedure to inhibit the development of tolerance to and dependence on morphine. Arzneimittelforschung, 20, 1596-1604, 1970.

50. Mayfield R.D, Suzuki F., Zahniser N.R.: Adenosine A2A receptor modulation of electrically evoked endogenous GABA release from slices of rat globus pallidus. J. Neurochem., 60, 2334-2337, 1993.

51. Michalska E., Malec D.: Agonists and antagonists of adenosine receptors and morphine withdrawal syndrome in rats. Pol. J. Pharmacol., 45, 1-9, 1993.

52. Miura T. et al.: Roles of mitochondrial ATP-sensitive K channels and $\mathrm{PKC}$ in anti-infarct tolerance afforded by adenosine A1 receptor activation. J. Am. Coll. Cardiol., 35, 238-245, 2000.

53. Munro R. et al.: Differential expression of adenosine A2A and A2B receptor subtypes on myeloid U937 and THP-1 cells: Adenosine A2B receptor activation selectively stimulates cAMP formation and inhibition of TNF- a release in THP-1 cells. Drug Dev. Res., 44, 41-47, 1998.

54. Noda Y., Nabeshima T.: Opiate physical dependence and N-methylD-aspartate receptors. Eur. J. Pharmacol., 500, 121-128, 2004.

55. O'Neill C. et al.: Adenosine A1 receptor mediated inhibition of dopamine release from rat striatal slices is modulated by D1 dopamine receptors. Eur. J. Neurosci., 26, 3421-3428, 2007.

56. Peyot M.L. et al.: Extracellular adenosine induces apoptosis of human arterial smooth muscle cells via A2B-purinoreceptor. Circ. Res., 86, 76-85, 2000

57. Rebola N. et al.: Adenosine A2A receptors are essential for long-term potentiation of NMDA-EPSCs at hippocampal mossy fiber synapses. Neuron, 57, 121-134, 2008.

58. Ribeiro J.A., Sebastião A.M., de Mendonca A.: Adenosine receptors in the nervous system: pathophysiological implications. Prog. Neurobiol., 68, 377-392, 2002. 
59. Robinson T.E, Berridge K.C.: Incentive-sensitization and addiction. Addiction, 96, 103-114, 2001.

60. Robinson T.E., Berridge K.C.: The incentive sensitization theory of addiction: some current issues. Phil. Trans. R. Soc. B., 363, 31373146, 2008.

61. Sawynok J.: Topical and peripherially acting analgesics. Pharmacol. Rev., 55, 1-20, 2003.

62. Schiffmann S.N., Jacobs O., Vanderhaeghen J.J.: Striatal restricted adenosine A2 receptor (RDC8) is expressed by enkephalin but not by substance P neurons: an in situ hybridization histochemistry study. J. Neurochem., 57, 1062-1067, 1991.

63. Sebastião A.M., Ribeiro J.A.: Adenosine receptors and the central nervous system. Handb. Exp. Pharmacol., 193, 471-534, 2009.

64. Shahidi S., Hashemi-Firouzi N.: The effects of a 5-HT receptor agonist and antagonist on morphine withdrawal syndrome in mice. Neurosci. Lett., 578, 27-32, 2014.

65. Shindou T. et al.: Adenosine A2A receptor enhances GABA (A)-mediated IPSCs in the rat globus pallidus. J. Physiol., 532, 423-434, 2001.

66. Song Y. et al.: Selective attenuation of isoproterenol-stimulated arrhythmic activity by a partial agonist of adenosine A1 receptor Circulation, 105, 118-123, 2002.
67. Spanagel R., Weiss F.: The dopamine hypothesis of reward: past and current status. Trends Neurosci., 22, 521-527, 1999.

68. Trescot A.M. et al.: Opioid Pharmacology. Pain Physician., 11, 133-153, 2008.

69. Van Schaick E.A. et al.: Metabolic and cardiovascular effects of the adenosine $\mathrm{A} 1$ receptor agonist $\mathrm{N}^{6}$-(p-Sulfophenyl) adenosine in diabetic zucker rats: Influence of the disease on the selectively of action. J. Pharmacol. Exp. Ther., 287, 21-30, 1998.

70. Vanderschuren L.J., Kalivas P.W.: Alterations in dopaminergic and glutamatergic transmission in the induction and expression of behavioral sensitization: a critical review of preclinical studies. Psychopharmacology, 151(2-3), 99-120, 2000.

71. Wardas J., Konieczny J., Lorenc-Koci E.: SCH 58261, an A(2A) adenosine receptor antagonist, counteracts parkinsonian-like muscle rigidity in rats. Synapse, 41(2), 160-171, 2001.

72. Wilcox C.S. et al.: Natriuretic and diuretic actions of a highly selective adenosine A1 receptor antagonist. J. Am. Soc. Nephrol., 10, 714-720, 1999.

73. Wolf M.E.: LTP may trigger addiction. Mol. Interv., 3, 248-252, 2003.

74. Wood P.L. et al.: Inhibition of nigrostriatal release of dopamine in the rat by adenosine receptor agonists: A1 receptor mediation. Neuropharmacology, 28, 21-25, 1989. 